\title{
COVID-19 en El Salvador, ¿priorizar la vida o priorizar la economía?
}

La enfermedad por coronavirus (COVID-19) ha marcado la historia del mundo en 2020 y ha traído cambios importantes en la dinámica cotidiana de las personas y de los países: ha cambiado la frecuencia y la forma en la que nos movilizamos en los diferentes espacios; ha acelerado y ampliado la adopción de tecnologías de la informática y de las comunicaciones como mecanismo para mantener contacto con seres queridos, para realizar teletrabajo y para el desarrollo de los procesos formales de enseñanza-aprendizaje, y, sobre todo, ha trastocado fuertemente la dinámica económica en todos los países. Precisamente, por este último elemento, se hizo popular el falso dilema "priorizar la vida o priorizar la economía".

En El Salvador, esta visión maniquea de la situación fue adoptada y difundida desde la Presidencia de la República ${ }^{1}$ y ha sido especialmente fructífera para salvaguardar la conducción sanitaria y económica del gobierno actual, de los llamados de atención sobre la arbitrariedad y la opacidad desde la que se toman y ejecutan decisiones de gran impacto sobre la población y sobre las finanzas públicas.

Sin embargo, esta aparente disyuntiva entre la vida y la economía suscita algunas reflexiones que se desarrollarán a continuación. La primera reflexión cuestiona la consideración de la economía como sinónimo de economía capitalista. La segunda retoma algunos señalamientos hacia el capitalismo como amenaza continua para la vida sobre el planeta; la tercera reflexión presenta argumentos según los cuales en El Salvador ni la vida ni la economía han sido prioridad, $y$, finalmente, se incluye un llamamiento para que la economía sea comprendida y realizada como interdependiente con la vida y no como contraposición a ella.

\section{La economía como sinónimo de economía capitalista}

Los textos básicos de economía plantean que el problema central del que debe ocuparse la ciencia económica es el de la asignación eficiente de los recursos. La eficiencia se ha erigido como el más importante (¿único?) problema económico: los abordajes convencionales tratan sobre personas hiperracionales que (solo) tienen preferencias y que toman decisiones racionales basadas en la lógica medio-fin.

1 Véanse las publicaciones en Twitter de la Secretaría de Prensa de la Presidencia con fecha 3 de abril de 2020. 
No obstante, si se parte de la premisa de que las personas somos seres con necesidades que deben ser atendidas para garantizar la vida, la eficiencia se ubica en un lugar diferente y más bien se coloca al centro de la economía el problema de la reproducción de la vida:

"el problema de la reproducción de la vida es (...) de hecho el problema fundamental de la praxis humana y el punto de partida de una economía de la vida" (Hinkelammert y Mora, 2009, p. 40).

Comprendida la economía en este sentido, la disyuntiva de la vida o la economía no aplica porque priorizar la vida implicaría necesariamente garantizar las condiciones materiales y sociales para que esta vida sea no solo posible, sino buena: el alimento, las medicinas, el agua, la vivienda, la salud, los cuidados. Así, desde la economía para la vida, la apuesta por la vida sería la apuesta por la economía y viceversa.

A su vez, la vida es más que solo la permanencia física de las personas (negación de la muerte). Defender la vida no es solamente garantizar la permanencia física; implica garantizar las condiciones materiales y naturales que hacen que las vidas permanezcan y que lo hagan de una "cierta" manera. Se trata de la procura de una vida que merezca la pena ser vivida (Pérez Orozco, 2010, p. 43).

Sin embargo, cuando la economía es dominada por los dictámenes del capital y particularmente en una situación como la suscitada por la pandemia del COVID-19, ahí aparece la confrontación entre la economía (capitalista) y las necesidades de la vida.

El capitalismo es un sistema económico que se cimienta sobre la propiedad privada de los medios de producción (tierras, capital dinero, inmobiliarios) y sobre la explotación del trabajo asalariado. Es un sistema económico cuya fuerza motriz es la búsqueda de la ganancia monetaria a escalas cada vez mayores y en el que la producción de las cosas útiles para vivir ocurre bajo esa lógica.

En las economías capitalistas, el mercado se erige como instancia máxima de la organización social y económica; la búsqueda de la ganancia es la fuerza motriz; el derecho a la propiedad y el lucro se superponen a cualquier otro derecho, y las personas persiguen el ideal de la autosuficiencia a través del mercado.

Esta quimera de la "autosuficiencia a través del mercado" muestra su fragilidad cuando hay crisis (Pérez Orozco, 2010, p. 43) y particularmente en una situación como la derivada de la pandemia COVID-19, que nos muestra que nos necesitamos mutuamente y que el mercado no es la instancia en la que la vida tenga algún valor por sí misma.

En un contexto en el que se habla de "economía" como quien habla únicamente del "circuito capitalista", adquiere sentido el llamado de atención para 
priorizar la vida antes que la economía. Pero esta disyuntiva aparece como una forma velada de reconocimiento de que la economía (capitalista) no tiene a las vidas humanas como su centro y que, por tanto, es necesaria una tregua en la que la vida humana (la permanencia física) sí ocupe el centro del quehacer económico y social, al menos mientras dure la pandemia.

En la economía salvadoreña, las actividades económicas capitalistas ocurren en concomitancia con otros procesos económicos, otras actividades que, aunque ocurran en un país cuya economía es dominada por la racionalidad de la ganancia (del capital), ellas mismas no tienen carácter capitalista: se trata de procesos de trabajo que no persiguen la lógica de la ganancia capitalista, sino la reproducción de la vida; son procesos económicos en los que, en países del submundo capitalista — en donde se ubica analíticamente a El Salvador-, encuentra ocupación la población no asalariada.

Con esto en mente, cabe pensar que, al confundir la economía con la economía capitalista, la supuesta priorización de la vida sobre la economía (capitalista) se convierte en su contrario, porque al restringir toda actividad económica (capitalista y no capitalista), se restringe no solo el empleo formal y los salarios ${ }^{2}$, sino también se restringe la procura de ingresos de la población trabajadora no asalariada; y si esta no recibe una contraprestación proporcional a la pérdida, se coloca en mayores dificultades al circuito económico con racionalidad de reproducción de la vida.

Por su parte, las empresas capitalistas tienen más recursos para resistir el distanciamiento físico, más recursos para innovar y para utilizar las tecnologías de la información y la comunicación para que su negocio no perezca o incluso crezca; ellas tienen recursos para resistir y, si no los tuvieran, es más probable que los consiguieran en el sector financiero o incluso en el sector público a través de la demanda de políticas de reactivación económica.

Pero los pequeños productores agrícolas, las personas asalariadas, las que trabajan en el sector servicios, las que venden en los mercados, las que producen mercancías para vender, esas personas son las que tienen más dificultades para resistir y menores posibilidades de conseguir financiamiento en el sector financiero capitalista, o bien tienen menor probabilidad de recibir apoyo estatal directo, oportuno y suficiente.

2 Según los datos del Instituto Salvadoreño del Seguro Social (ISSS), en junio de 2020, se reportaron 63,245 cotizantes en planilla menos, comparado con junio de 2019, lo cual supone un retroceso de al menos cuatro años en la generación de empleo formal. Por su parte, el salario nominal promedio para cotizantes del sector privado ha pasado de $\$ 552.26$ mensuales en junio de 2019 a $\$ 482.5$ mensuales en junio de 2020. Eso supone una reducción nominal del $12.6 \%$ en un año. 


\section{La economía capitalista como amenaza continua para la vida so- bre el planeta}

El supuesto dilema "la vida o la economía" en el contexto de la pandemia ha sido desmentido desde diferentes perspectivas. Una de estas perspectivas es la de la directora gerente del Fondo Monetario Internacional (FMI), Kristalina Georgieva:

"Yo digo que este dilema es falso. Dado que se trata de una crisis pandémica, es necesario derrotar al virus y proteger la salud de las personas para alcanzar la recuperación económica" (Georgieva, 2020).

La postura expresada por Georgieva deja intacta una reflexión que, aunque necesaria, no es esperable por parte del organismo financiero que ella dirige: cuál es el lugar que ocupan las personas en la economía capitalista, especialmente en el capitalismo neoliberal.

Las personas que no poseen medios de producción se ubican en el sistema capitalista como fuerza de trabajo que produce la riqueza, pero que solo participan de una parte (más o menos pequeña) de esa riqueza. Sin fuerza de trabajo, no habría producción capitalista; sin producción, no habría mercancías ni ganancias monetarias, ni consumidores para esas mercancías. Es necesario, por tanto, proteger a las personas que constituyen la fuerza de trabajo y la población consumidora, para que la economía (capitalista) se recupere.

Puesto en los términos anteriores, la afirmación de que "al proteger la vida de la fuerza de trabajo y de la población consumidora se sientan las bases de la recuperación del capitalismo mundial" sería muy impopular, pues pondría de manifiesto que no hay una preocupación genuina por la vida humana por ser ella un bien valioso en sí misma, sino por ser ella una condición sine qua non para la sobrevivencia de una forma particular de economía: el capitalismo.

Sin embargo, hay mucha evidencia de que la búsqueda de la ganancia como fuerza motriz que orienta el sistema económico no ve a la vida en general como un valor en sí misma, y ello aplica también para la vida humana en particular. El capitalismo ha alimentado (o al menos desatendido) otras problemáticas que diezman la vida de millones de personas: el hambre, las guerras, la migración indocumentada y los desplazamientos forzados por la violencia, el cambio climático, la morbilidad asociada al estilo de vida imperante, entre otras.

Además, la dinámica capitalista en su versión neoliberal ha dejado a las economías pobres en una posición desventajosa para enfrentar los shocks externos, en general, y esta pandemia, en particular: tienen sistema de salud debilitados y sin cobertura universal, y una población trabajadora empobrecida 
tanto en términos absolutos (pobreza monetaria y multidimensional) ${ }^{3}$ como en términos relativos (desigualdad en la distribución del ingreso).

La mercantilización de derechos, entre ellos el de salud y el de educación, ha hecho que el impacto en los países más pobres sea peor. Lo reconoce la misma directora del FMI:

"Los países de mercados emergentes y de bajo ingreso —en África, América Latina y gran parte de Asia - enfrentan un alto riesgo. Dado que sus sistemas sanitarios son más débiles para empezar, muchos se enfrentan al terrible desafío de luchar contra el virus en ciudades densamente pobladas y barriadas asoladas por la pobreza, donde el distanciamiento social difícilmente es una opción. Con menos recursos para empezar, están gravemente expuestos a los shocks de demanda y de oferta, y al drástico endurecimiento de las condiciones financieras que se están produciendo, y algunos pueden enfrentar una carga de la deuda insostenible" (Georgieva, 2020).

Aunque este señalamiento del FMI es pertinente, no se hace ninguna mención de la responsabilidad que en esta situación juega el modelo económico neoliberal, aun cuando el mismo FMI ha señalado lo pernicioso que ha sido para algunas economías el ajustarse a una política fiscal contractiva como mecanismo para, supuestamente, reducir la relación de la deuda respecto al Producto Interno Bruto (PIB), y para el beneplácito de las calificadoras de riesgo y de los acreedores, que juegan un papel crucial en las condiciones más o menos favorables que tienen las economías necesitadas de financiamiento para acceder a él.

"Las políticas de austeridad no solo acarrean sustanciales costos para el bienestar a través de los canales del lado de la oferta, sino que también perjudican la demanda, agravando el empleo y el desempleo (...) En suma, los beneficios de algunas políticas que constituyen una parte importante de la agenda neoliberal parecen ser algo exagerados" (Furcery, Loungani \& Ostry, 2016, p. 40).

Así pues, sin demeritar el papel que ha jugado la gestión gubernamental de los países pobres en la gestación y profundización de la debilidad de sus respectivas economías, es necesario recordar que la organización económica mundial que coloca en la cúspide el capital difícilmente pone en los primeros lugares de la agenda de preocupaciones la vida humana o la vida en general; máxime si al hacer esto se socava la base de la rentabilidad del capital, ya sea porque se le amenaza con impuestos más progresivos, con una legislación laboral más protectora para la fuerza de trabajo, con requerimientos ambientales más estrictos, o con un marco legal que reconozca y tutele el derecho humano al agua, por poner algunos ejemplos.

3 En América Latina, la Comisión Económica para América Latina (CEPAL) estima que la atención a la emergencia y el paro económico derivado de ella agregará 27.2 millones de personas a los 187.4 millones que ya estaban en pobreza antes de la emergencia sanitaria y la crisis económica (CEPAL/OIT, 2020, p. 5). 
De hecho, el riesgo de enfrentar nuevas y peores pandemias ha sido señalado por personas dedicadas a la investigación científica en ciencias naturales, quienes han estudiado los impactos que tiene la forma y el ritmo de producción actual, y la forma de consumo que le corresponde -el consumismosobre el entorno natural y la zoonosis ${ }^{4}$.

Como contrapunto, hay quienes defienden la idea de que el capitalismo no es la amenaza, sino la tabla de salvación, ya que es el único que, cuando funciona adecuadamente, ofrece los incentivos que impulsan el desarrollo tecnológico que permite a la humanidad soslayar los límites que impone la naturaleza a la expansión económica ilimitada, y que mejora la vida de las personas con más y mejores satisfactores para sus necesidades. Incluso, algunas personas ven con preocupación que las protestas sociales pongan sus ojos sobre el sistema de libre mercado (neoliberal):

"Así, empezamos a ver confusión en el lenguaje de protestas que tienen un origen absolutamente válido y que reclaman cambios que hace mucho debieron ocurrir. Repentinamente las protestas son también contra el capitalismo, contra el neoliberalismo, o contra la globalización (...) Nuestra sociedad parece ignorar que una crisis como esta subraya la colosal importancia de la inversión privada en la investigación científica y médica que todos los días logra encontrar soluciones a enfermedades que antes eran mortales, y a condiciones que afectan seriamente la calidad de vida de millones de seres humanos (...) En este momento en el que los jóvenes protestan por causas justas e impostergables, vale la pena recordarles la importancia de la empresa privada (...) Hay que recordarles que no hay una sola medicina remotamente relevante que haya sido originada en un país que no sea capitalista" (Suárez-Vélez, 2020).

Este llamamiento a reconocer y valorar el aporte de las empresas privadas capitalistas podría tomarse como una advertencia de que ni el Estado ni otra entidad pueden relevarlas de su papel en el progreso de la humanidad; advierte de que son ellas las llamadas a desempeñar un papel en el que no puede ser sustituidas.

Pero el mito de que no hay -o no habría - ni desarrollo científico ni innovación fuera de las empresas privadas (capitalistas) ha sido refutado por la economista Mariana Mazzucatto, quien ha destacado que las inversiones estatales han sido clave para los avances tecnológicos sobre los que descansan las grandes corporaciones que se presentan como referentes de la investigación e innovación (Mazzucato, 2014). Como este, hay varios otros mitos con los que el orden capitalista se legitima y evita incluso los cambios más tímidos en favor de una economía para la vida.

\section{En El Salvador, ni la vida ni la economía han sido prioridad}

Como se desarrolló previamente, al comprender la economía como el proceso mismo de generación de las condiciones para la producción y ..........................

4 Véase, por ejemplo, la entrevista a la epidemióloga y veterinaria Delia Grace (Martins, 2020) y las declaraciones de la profesora Kate Jones (Gill, 2020). 
reproducción de la vida, una situación como la presentada por la pandemia, lejos de implicar una disyuntiva entre economía y vida, lo que pone de manifiesto es la interdependencia entre ambas: salvar la vida de las personas no es posible si no se garantizan las condiciones materiales para su reproducción (economía).

En El Salvador, las directrices económicas no responden a las necesidades de la reproducción de la vida, particularmente en las últimas tres décadas. La apuesta por la vida no estaba al centro de las reformas estructurales con las que se impulsó el neoliberalismo.

En un país cuya historia está marcada por la violencia institucionalizada, la vida no es valorada como un bien preciado; de ello da cuenta la epidemia de homicidios (36 por cada 100,000 habitantes en 2019), la migración indocumentada hacia Estados Unidos, la provisión deficiente en calidad y cantidad de servicios públicos de salud, y el estrangulamiento financiero del Estado, situación esta última que reduce al mínimo el margen de maniobra desde el punto de vista fiscal. Esa debilidad estatal para ofrecer protección a la población es, por tanto, una muestra fehaciente de que, en la adopción, implementación y consolidación del modelo neoliberal en El Salvador, se priorizó al capital por sobre la vida de las personas y por sobre la economía.

¿Es posible, entonces, en el marco del capitalismo, mejorar las condiciones de vida para la población salvadoreña? Sí, es posible. Pero lograrlo supone organización y presión social para que prominentes las figuras económicas, políticas y mediáticas más reaccionarias en cuanto a la vigencia del modelo económico neoliberal y sus preceptos abran su perspectiva y den paso a una redefinición del papel del Estado salvadoreño en la economía.

Ciertamente "mayor" intervención estatal no significa automáticamente "mejor" intervención, pero el dotar de más recursos económicos, institucionales y técnicos al Estado incrementa la probabilidad de una mejora en la calidad de vida de la población a la que el mercado no "incluye" por no ser competitiva: la población con baja educación, con una salud débil, con una situación de vivienda precaria y habitante de barrios y municipios marcados y estigmatizados por la presencia de pandillas, por poner algunos ejemplos.

Renunciar al modelo neoliberal no amenaza el capitalismo; y mientras el capitalismo sea la forma de producción y consumo dominante, la vida humana y no humana sobre el planeta está amenazada por la voracidad de la expansión del capital. No obstante, la renuncia al modelo neoliberal daría una bocanada de esperanza en los países cuyas economías languidecen y cuyas poblaciones sufren la exclusión social propia de las sociedades que se han abandonado a un libre mercado que no es más que la dominación más o menos irrestricta del capital. 


\section{Una economía para la vida frente al capital}

La pandemia del COVID-19 ha mostrado la fragilidad de la vida humana, no solo en términos del contagio y la muerte por coronavirus, sino también en cuanto pone en evidencia las desigualdades y la vulnerabilidad social, económica, política y ambiental en la que la mayor parte de las personas desarrolla su vida, especialmente en El Salvador.

El confundir economía y capitalismo esconde la amenaza continua que representa el capital para la vida no solo durante la pandemia del COVID-19, sino desde antes y después de este episodio particular de la historia de la humanidad. La economía para la vida no requiere decidir entre ella misma y la vida; es en la economía capitalista donde se pone la actividad económica en contradicción con la vida durante la pandemia.

Por tanto, posicionarse a favor de la vida desde una perspectiva "radical" implica subvertir el capitalismo como forma de producción dominante. Sin embargo, desde una perspectiva más "conservadora", ese juicio y afán de cambio se dirige "al menos" al modelo económico neoliberal, que acentúa aún más el carácter voraz del capital.

El Departamento de Economía de la UCA ha presentado en diferentes ocasiones una propuesta en esta última línea: redireccionar al capitalismo salvadoreño hacia una modalidad con mayor proporcionalidad entre los sectores de la actividad económica y con mayor inversión en la fuerza productiva principal (las personas) (Departamento de Economía de la UCA, 2017).

Otras propuestas son, por ejemplo, el impulso de un Acuerdo Nacional por el pleno empleo y el desarrollo en El Salvador (Cabrera Melgar, 2020); o bien, la "transformación de la matriz productiva", según los cuales es necesario un cambio de paradigma político y económico para impulsar la producción para la economía nacional, considerando, entre otras cosas, la desigualdad entre territorios (Coreas y Salgado, 2019).

Sin embargo, hasta ahora, no se vislumbra la conversión de la vida en una prioridad en El Salvador, ni desde una perspectiva radical ni tampoco desde una perspectiva conservadora. Sin el reconocimiento del modelo neoliberal como un obstáculo para que la economía esté más en consonancia con la vida de la mayoría de la población, la retórica de la vida como prioridad carece de contenido. 


\section{Referencias bibliográficas}

Cabrera Melgar, O. (2020). El Salvador necesita un pacto nacional por el pleno empleo y el desarrollo inclusivo ante el Covid-19. Fundación para el Desarrollo de Centroamérica. https://www.fudecen.org/wp-content/ uploads/2020/08/El-Salvador-en-tiempos-del-COVID-19.-LESCO2020.pdf

Comisión Económica para América Latina (CEPAL)/Organización Internacional del Trabajo (OIT). (2020). Coyuntura Laboral en América Latina y el Caribe. El trabajo en tiempos de pandemia: desafío frente a la enfermedad por coronavirus (COVID-19). Organización de las Naciones Unidas (ONU). https://www.cepal.org/es/publicaciones/45557-coyuntura-laboral-america-latinacaribe-trabajo-tiempos-pandemia-desafios-frente

Coreas, V. y Salgado, M. (2019). La matriz productiva en El Salvador y su camino hacia la transformación. Friedrich Ebert Stiftung. https://ibrary.fes.de/ pdf-files/bueros/fesamcentral/15585.pdf

Departamento de Economía de la UCA. (2017). Análisis socioeconómico de El Salvador, segundo semestre de 2016. Universidad Centroamericana "José Simeón Cañas". http://www.uca.edu.sv/economia/wp-content/uploads/ ASES-segundo-semestre2016_VW-corregido2019.pdf

Furcery, D., Loungani, P. y Ostry, J. (2016). El neoliberalismo, cun espejismo? Finanzas \& Desarrollo, 38-41. https://www.imf.org/external/pubs/ft/fandd/ spa/2016/06/pdf/ostry.pdf

Georgieva, K. (9 de abril de 2020). Afrontar la crisis: Prioridades para la economía mundial [Discurso]. Fondo Monetario Internacional. https://www.imf. org/es/News/Articles/2020/04/07/sp040920-SMs2020-Curtain-Raiser

Gill, V. (9 de junio de 2020). Esta no es la última pandemia: la advertencia de los científicos ante la "tormenta perfecta" para nuevas enfermedades. BBC News Mundo. https://www.bbc.com/mundo/noticias-52986518

Hinkelammert, F. y Mora, H. (2009). Por una economía orientada hacia la reproducción de la vida. Íconos. Revista de Ciencias Sociales, 33, 39-49. http:// coleccion.uca.edu.sv/franz-hinkelammert/items/show/4673

Martins, A. (21 de julio de 2020). El mundo está tratando los síntomas de la pandemia de covid-19, pero no las causas. BBC News Mundo. https://www. bbc.com/mundo/noticias-53435056

Mazzucato, M. (2014). El Estado emprendedor: mitos del sector público frente al privado. RBA Libros, S.A. 
Pérez Orozco, A. (2012). Crisis multidimensional y sostenibilidad de la vida. Investigaciones Feministas, 2, 29-53. https://doi.org/10.5209/rev_INFE.2011. v2.38603

Suárez-Vélez, J. (22 de junio de 2020). Desigualdad y capitalismo. Letras Libres. https://www.letraslibres.com/mexico/economia/desigualdad-y-capitalismo 